\title{
Anterior Spinal Stabilization and Fusion in Cervical Spinal Trauma
}

\author{
Muhammad Arshad* \\ Department of Neurosurgery, Quaid-E-Azam medical college (qamc)/Bahawal Victoria Hospital (bvh), Pakistan
}

Submission: November 23, 2016; Published: January 23, 2017

*Corresponding author: Muhammad Arshad, Associate professor of neurosurgery, quaid-e-azam medical college (qamc)/bahawal Victoria

hospital (bvh), Bahawalpur, Pakistan, Email: dr_arshadpk@yahoo.com

Abstract

It is a prospective study of 30 cases of Cervical Spinal Trauma in which anterior cervical spinal stabilization and fusion was performed. Study span is three years, i.e from July 2005 to June 2008 with follow up period of one year and it was carried out in the Department of Neurosurgery, Quaid-e-Azam Medical College /Bahawal Victoria Hospital Bahawalpur.

Purpose of Study: It was to find out the efficacy and benefits of anterior cervical spinal stabilization procedures in cases of cervical trauma.

Methodology: 30 cases of cervical spinal trauma were included in this study. The Age range was 15 years to 40 years. Twenty three (23) were males and seven (7) were females with male to female ratio of 3.2:1.Most common cause of cervical spinal injury was road traffic accidents and most common site of traumatic involvement was C5/C6 cervical spinal level. All the patients were belonging to poor and middle socioeconomic class. Nine (9) patients sustained complete cervical cord injury and they were quadriplegic and remaining twenty one (21) patients were quadripretic as a result of partial cervical cord injury. All patients were assessed clinically and radio logically. Plain X-Rays of cervical spine, AP\&LAT. views, C-T scan and MRI of cervical spine were obtained to get information of injuries in detail. In almost all the cases, anterior two columns of spine were disrupted resulting in instability and cord compression. In all the cases cervical traction was applied to get align the cervical column first and then anterior fixation and fusion was performed. All patients were mobilized early after surgery.

Results: Nine (9) cases with complete cord injury did not improve neurologically after surgery. Eleven (11) patients with partial cord injury and power of G $3 / 5$ before surgery improved to G 4+/5 after surgery and ten (10) patients with power G $2 / 5$ before surgery improve to G $3 / 5$ after surgery. All patients were out of bed early, to prevent the complications of being bed ridden for long time.

Conclusion: Anterior cervical spinal fixation and fusion is an excellent way of cervical spinal stabilization in cases of cervical trauma Patients improve neurologically with these procedures and they are mobilized early from the beds to prevent complications of being bed ridden for longer periods of time.

Keywords: Cervical spinal trauma; Neurological status; Anterior cervical stabilization; Spinal column; Cervical traction

\section{Introduction}

The vast majority of traumatic spinal column injuries involve the cervical spine, the most mobile and dynamic portion of the spinal column. The incidence of cervical spinal injuries compared to the thoracic, lumbar and thoraco lumbar level is about $60 \%$ of all these levels.

The most common cause of cervical spine injury is motor vehicle accidents, followed by falls. The vast majority of injuries occur in patients 15-30 years old. Males are three to four times as likely to sustain a traumatic vertebral column injury as females. The cause of spinal injury varies with age; notably the very young are the most commonly victim of pedestrian motor vehicle accidents and the very old most commonly suffer falls [1].
Spinal cord injury occurs through various countries throughout the world with an annual incidence of 15 to 40 cases per million, with the causes of these injuries ranging from motor vehicle accidents and community violence to recreational activities and workplace-related injuries. Survival has improved along with a greater appreciation of patterns of presentation, survival, and complications [2].

Cervical Spine (c-spine) injuries are the most feared of all spinal injuries because of the potential for significant deleterious sequelae. In a 1995 study from russia, 196 patients with spinal cord injury were admitted over 5 years in one centre. Injuries were: cervical, 49.0\%; thoracic, 27.5\%; and lumbar, $23.5 \%$ [3]. In the United States, $1.9-3.8 \%$ of adult emergency room presentations are 
for acute c-spine injury due to blunt trauma [4] and as many as 10\% of unconscious patients injured in motor vehicle accidents (MVas) have c-spine injury [5]. Motor vehicle accidents, falls and sport trauma are responsible for the majority of emergency department presentations of c-spine injuries [5]. Most common level of cervical spinal column injury is C5/C6 followed by C6/C7 level. And most appropriate management for cervical spinal trauma is:-early diagnosis, proper alignment, effective decompression of neural elements and useful stabilization for early recovery [3].

\section{Materials and Methods}

Thirty (30) cases of cervical spinal trauma were included in this study. Age range was from 15 years to 40 years. Twenty three (23) were males and seven (7) were females. Most common cause of cervical spinal injury (in 15 patients ,50\%) was road traffic accidents and other causes were falls (in10 patients ,33.33\%) from height and few sports injuries (in 5 patients, 16.66\%). Most common site of traumatic involvement was C5/C6 cervical spinal level (20 cases, 66.66\%). In (6 cases, 20\%) C6/C7 level was injured and in other (4 cases, $13.33 \%$ ) C3/C4 level was disrupted. All the patients were belonging to poor and middle socio economic class and most were labourers.

In twenty two $(22,73.33 \%)$ cases there was fracture/dislocation of cervical spine, five $(5,16.66 \%)$ cases have had compression fracture with retropulsion of vertebral body, causing compression of spinal cord and other three $(3,10 \%)$ cases had disrupted intervertebral discs in which prolapsed pieces of disc material were impinging upon the spinal cord.

Regarding neurological status, nine $(9,30 \%)$ patients sustained complete cervical cord injury and they were quadriplegic after injury and other twenty one $(21,70 \%)$ patients were quadripretic as a result of partial cervical cord injury. Eleven $(11,52.38 \%)$ cases in partial injury group had power of $\mathrm{G} 3 / 5$ with intact sensations, with some degree of sphincter dysfunction and ten $(10,47.6 \%)$ patients had power of G 2/5 with sensory and sphincter dysfunction as well.

All patients were assessed clinically and radiologically. Plain X-Rays of cervical spine, AP\&LAT. views, C-T scan and MRI of cervical

Table 1: Out come after surgery. spine were obtained to gather the details of injury. In almost all the cases anterior two columns of spine were disrupted resulting in instability and cord compression. In all the cases cervical traction was applied to get align the cervical column first and then anterior fixation and fusion was performed. In this procedure, after getting alignment of cervical spine by applying the cervical traction (Crutch Field cervical Traction) defective vertebral body along with upper and lower discs were removed (corpectomy and discectomy was performed) or disrupted disc material was removed, spinal cord and neural elements were decompressed, bone graft taken from the iliac crest (Autograft) was applied there and anterior plate fixed with the help of self locking screws.

When the injury was at C4/C5 and C5/C6 level, cervical spine was approached from the right side and in cases, where injury was at C6/C7 level, spine was exposed from the left side to prevent the damage to the recurrent laryngeal nerve which is vulnerable to injury by right sided approach when the lesion is at C6/C7 level.

All patients were mobilized early after surgery within three (3) days and were discharged to home after one week. Patients were advised to wear Philadelphia cervical collar for six (6) week after surgery to take care of there spine from any inadvertent injury or jerk.

\section{Results}

Cervical Spinal alignment was achieved in all the cases after applying cervical traction. Nine $9(30 \%)$ cases with complete cord injury did not improve neurologically after surgery. Eleven $11(36.66 \%)$ patients with partial cord injury and power of G 3/5 before surgery improved to $\mathrm{G} 4+/ 5$ after surgery and their sphincter's function also improved .They were found independent regarding their daily needs during follow up period. Ten $10(33.33 \%)$ patients with power of $\mathrm{G} 2 / 5$ before surgery improved to $\mathrm{G} 3 / 5$ after surgery (Table 1). Their sensory system and sphincter dysfunction also improved to some extent after surgery and continued to improve during follow up period of one year. They did need less support for their daily activities during follow up period.

\begin{tabular}{|c|c|c|c|c|c|}
\hline Sr.No & Spinal cord injury & Extent of Deficit & No. of Patients & Percentage & Out Come \\
\hline 1 & Partial & $\begin{array}{c}\text { a)Power G } 3 / 5 \text { b)Sensations } \\
\text { Intact c) Mild to Moderate } \\
\text { Sphincter dysfunction }\end{array}$ & 11 & $36.66 \%$ & $\begin{array}{c}\text { very good. Independent } \\
\text { regarding their daily activities }\end{array}$ \\
\hline 2 & Partial & $\begin{array}{c}\text { a)Power G 2/5 b) Some Sensory } \\
\text { Deficit c) Moderate to Severe } \\
\text { Sphincter Dysfunction }\end{array}$ & $\begin{array}{c}\text { Good. Improved to an extent } \\
\text { for less support for daily needs. }\end{array}$ \\
\hline 3 & Complete & $\begin{array}{c}\text { Loss of total cord functions } \\
\text { below the level of injury }\end{array}$ & 9 & $30 \%$ & No improvement at all but \\
early mobilized after surgery.
\end{tabular}


There were few complications as well (Table 2). Wound infection in (4) four (13.33\%) cases which was treated by daily wound dressing and antibiotics after obtaining culture and sensitivity and were cured within two week time. Dural tear and CSF leakage in two $2(6.66 \%)$ cases which were treated by head elevation and lumbar drainage of CSF. And these patients were also cured within fifteen (15) days. Five 5 (16.66\%) patients with complete cord lesion developed bed sores, those had to be treated surgically with flap rotation (Table 2).

Table 2: Complication of surgery and trauma.

\begin{tabular}{|c|c|c|c|}
\hline Sr. No & $\begin{array}{c}\text { Name of } \\
\text { Complication }\end{array}$ & $\begin{array}{c}\text { No. of } \\
\text { Complication }\end{array}$ & Percentage \\
\hline 1 & Wound Infection & 4 & $13.33 \%$ \\
\hline 2 & Dural Tear & 2 & $06.66 \%$ \\
\hline 3 & Bed Sores & 5 & 16.6 \\
\hline
\end{tabular}

All patients were mobilized early from their beds to prevent the complications of being bed ridden for longer periods of time and this was the main goal of cervical fixation and fusion procedures in these trauma cases.

\section{Discussion}

Over the past years, significant advances has taken place in basic research, imaging and in the treatment of cervical spine injuries. The pathophysiological understanding of spinal cord injury has been considerably improved by the basic research. Current management of spinal trauma is based on four principles: timely diagnosis, fracture reduction, spinal cord decompression and efficient immobilization to permit healing. Numerous methods of treatment has been developed to achieve anatomical alignment and optimal stability without decreasing vertebral column flexibility [3]. We applied all these four principles for the management of our cervical spine injured patients.

All patients undergoing surgical treatment for an acute cervical spinal injury with neurologic deficit at two institutions between March 1989 and May 1991 were reviewed retrospectively. Fortythree patients initially were evaluated. At one institution, patients with neurologic spinal injuries had surgical intervention within 72 hours of injury. At the other institution, patients underwent immediate closed reduction with subsequent observation of neurologic status for 10 to 14 days before undergoing surgical stabilization. This study indicates that patients who sustain acute traumatic injuries of the cervical spine with associated neurologic deficit may benefit from surgical decompression and stabilization within 72 hours of injury. Surgery within 72 hours of injury in patients sustaining acute cervical spinal injuries with neurologic involvement is not associated with a higher complication rate. Early surgery may improve neurologic recovery and decrease hospitalization time in patients with cervical spinal cord injuries [4]. Although our patients did not undergo early surgery as indicated in this study, even though our patients improved by later surgery as well.
All victims of major blunt trauma have been said to be at risk of cervical spinal injury. In a prospective study of 410 such patients at our institution, we identified 13 patients ( 6.12 per cent) with unstable cervical spines. Loss or defect of consciousness following injury (regardless of duration), neurological deficit consistent with cervical cord or nerve root injury and neck tenderness were significantly predictive of an unstable cervical spine. Immediate radiographic investigation of the cervical spine is mandatory in such patients, but may not be required in patients without these signs [5]. So all our patients were investigated fully by X-Rays, CT scan and MRI to obtain the details of injuries and evidences of instability.

The cervical spine locking plate is theoretically safer than the Caspar system because the posterior vertebral body cortex is not breached by the fixation screws, and the screws are less likely to back out anteriorly and irritate the esophagus. According to these results, the cervical spine locking plate system is biomechanically equivalent to and in some cases more stable than the Caspar system for fixation of a severe compressive flexion injury [6]. In all our patients, we used the cervical spine locking plate system due to its usefulness as mentioned in this article [7-10].

\section{Conclusion}

Anterior cervical spinal fixation and fusion is an excellent method of spinal stabilization in cases of trauma and other problems of cervical spine like tumors infections and degenerative diseases. It is especially indicated in cases where the vertebral bodies have been destroyed by the trauma and other disease processes and there is disruption of anterior two columns of spine. It is much more promising in cases of partial spinal cord injuries when there is sparing of some cord functions. Even it is fruitful in complete cord injuries because in those cases, patients are early mobilized from the beds after stabilization procedures so that they are saved from the complications.

\section{References}

1. Mark N Hadley (1994) Injuries to the Cervical Spine. Principles of Neurosurgery. By Setti S Rengachary, Robert H Wilkins (Eds.), MosbyYear Book Europe, p. 20-22.

2. Sekhon LH, Fehlings MG (2001) Epidemiology, Demographics, and Pathophysiology of Acute Spinal Cord Injury. Spine 26(24 Suppl): S2S12.

3. J Ramsbacher, M Brock (1999) Cervical Spinal Trauma. Critical reviews in Neurosurgery 9(6): 331-334.

4. Mirza SK, Krengel WF , Chapman JR, Anderson PA, Bailey JC, et al. (1999) Early Versus Delayed Surgery for Acute Cervical Spinal Cord Injury. Clin Orthop Relat Res 359: 104-114.

5. Ross SE, O'Malley KF, DeLong WG, Born CT, Schwab CW (1992) Clinical predictors of unstable cervical spinal injury in multiply injured patients. Injury 23(5): 317-319.

6. Grubb MR, Currier BL, Shih JS, Bonin V, Grabowski JJ, et al. (1998) Biomechanical Evaluation of Anterior Cervical Spine Stabilization. Spine 23(8): 886-892.

7. Walid MS, Zaytseva NV (2009) Upper cervical spine injuries in elderly patients. Aust Fam Physician 38(1-2): 43-45. 
8. Sonntag VKH, Volmer DG (2004) Spine. In: Winn HR (Ed). Youmans Neurological Surgery ( $5^{\text {th }}$ edn), Philadelphia: Saunders, pp. 4869-4885

9. Wang MC, Pintar F, Yoganandan N, Maiman DJ (2009) The continued burden of spine fractures after motor vehicle crashes. J Neurosurg Spine 10(2): 86-92.
10. Duane TM, Dechert T, Wolfe LG, Aboutanos MB, Malhotra AK, et al. (2007) Clinical examination and its reliability in identifying cervical spine fractures. J Trauma 62(6): 1405-1408.

\section{Your next submission with Juniper Publishers} will reach you the below assets

- Quality Editorial service

- Swift Peer Review

- Reprints availability

- E-prints Service

- Manuscript Podcast for convenient understanding

- Global attainment for your research

- Manuscript accessibility in different formats

( Pdf, E-pub, Full Text, Audio)

- Unceasing customer service

Track the below URL for one-step submission https://juniperpublishers.com/online-submission.php 